\title{
Educación (en línea) para el desarrollo sostenible
}

\section{(Online) education for sustainable development}

\section{Gemma Carbó Ribugent ${ }^{\mathrm{a}}$ y Roser Servalls Munar ${ }^{\mathrm{b}}$}

${ }^{a}$ Museu de la Vida Rural y profesora de la Universitat de Girona, gcarbo@museuvidarural.cat ${ }^{b}$ Museu de la Vida Rural, rservalls@museuvidarural.cat

\section{Resumen}

En el contexto de confinamiento domiciliario durante la primera ola de la pandemia mundial originada por el virus COVID-19, el equipo educativo del Museu de la Vida Rural diseñó y publicó una propuesta pedagógica virtual llamada «SOStenibilidad en juego». Dicha propuesta pretende generar conversaciones en el entorno familiar que posibiliten cambios de actitudes $y$ hábitos hacia la sostenibilidad a la vez que se descubren de forma lúdica y a través del arte y la cultura los 17 Objetivos para el Desarrollo Sostenible (ODS) establecidos por la UNESCO y la Agenda 2030.

Al observar que esta propuesta online no obtuvo la participación por parte de las familias que el equipo educativo del museo esperaba, la investigaciónacción que se expone en esta comunicación parte de la hipótesis de que dicha propuesta tendría más impacto implementada en centros de educación primaria cercanos al museo y a través del acompañamiento de sus educadoras $y$ de las maestras. En este artículo se da cuenta de una experimentación que permitió activar el material en las escuelas afines al proyecto educativo del museo y revisar la propuesta virtual con el objetivo de mejorarla y completarla tanto para público familiar como escolar.

Palabras clave: ODS, escuela, familias, impacto, propuesta virtual. 


\section{Abstract}

In the context of home confinement during the first wave of the global pandemic caused by the COVID-19 virus, the Museum's of the Rural Live educational team designed and published a virtual pedagogical proposal called "Sustainability at play". This proposal aims to generate conversations in the family environment that make possible changes in attitudes and habits towards sustainability while discovering in a playful way and through art and culture the 17 Goals for Sustainable Development established by UNESCO and the 2030 Agenda.

When observing that this online proposal did not obtain the participation of the families that the museum's educational team expected, the research action that is exposed in this communication is based on the hypothesis that the proposal would have more impact implemented in centers of primary education close to the museum and through the accompaniment of its educators and teachers. This article reports on an experimentation that allowed activating the material in schools related to the museum's educational project and reviewing the virtual proposal with the aim of improving and completing it for both family and school audiences.

Keywords: SDG, school, families, impact, virtual proposal. 


\section{Introducción: El Museu de la Vida Rural y la educación para el desarrollo sostenible}

El Museu de la Vida Rural (MVR) se inauguró en 1988 en la antigua casa de la familia Carulla, en L'Espluga de Francolí (Catalunya), con el objetivo de preservar y difundir el legado del mundo rural mediterráneo. Lluís Carulla i Canals, fundador del MVR, fue consciente del valor de un patrimonio de costumbres y tradiciones fruto de un legado de cultura y sabiduría que se remonta a muchos siglos atrás.

En 2009, tras un proceso de ampliación y modernización de la exposición permanente, el museo extendió su discurso al presente y al futuro del mundo rural con el objetivo de convertirse en un actor central a nivel internacional en el campo de la cultura, la ruralidad y el desarrollo sostenible.

La vida tradicional en las zonas rurales incidía en el desarrollo de capacidades específicas relacionadas con el uso de los recursos naturales y la organización de las comunidades en una economía circular y comunal (Algarra 2015). La revolución industrial y los procesos de urbanización supusieron el fin de esa situación. Buenos ejemplos del pasado, pero también malas prácticas, así como los efectos de la transición de la realidad rural a la urbana, suponen un conocimiento que hoy parece ser necesario si el modelo capitalista de desarrollo necesita ser cambiado hacia un modelo más sostenible.

Las exposiciones temporales y las actividades que se llevan a cabo en el museo giran en torno a temas clave como la aparición de materiales como el plástico, la gestión de los recursos hídricos, las energías limpias, el transporte sostenible, la economía circular y los oficios tradicionales, la gestión forestal, o reflexiones sobre otros temas relacionados con sostenibilidad, como la igualdad de género.

El MVR está comprometido con educar para la sostenibilidad a través de la cultura y las artes. Para ello, su proyecto educativo conecta la labor del museo con las agendas globales a nivel europeo e internacional: la Hoja de Ruta de la UNESCO para la Educación Artística (UNESCO 2006) y los objetivos educativos de la Agenda 2030 para el Desarrollo Sostenible (UNESCO 2017), que suponen una apuesta de transformación y mejora de la vida de las personas, sin excluir a nadie, y respetando el planeta.

Tomando como modelo la agrupación que las Naciones Unidas (ONU) proponen para los Objetivos de Desarrollo Sostenible (ODS), el proyecto educativo del museo estructura las actividades educativas y culturales en torno a las $5 \mathrm{P}$ (planeta, personas, partenariado, prosperidad y paz), apuntando cada una de ellas a Objetivos de Desarrollo Sostenible específicos.

Los museos pueden y deben jugar un papel importante en el reto de avanzar hacia la sostenibilidad. Sacha Kagan ha argumentado que la sostenibilidad consiste en reinventar mundos; es un proyecto cultural (Kagan, 2015). El plan estratégico 2019-2026 del MVR y el proyecto pedagógico articulan espacios y recursos para aprender y reflexionar sobre la sostenibilidad desde una perspectiva poliédrica que combina la mirada ambiental con la 
social, económica y cultural. Las educadoras del museo conciben los procesos de aprendizaje como la adquisición de habilidades y competencias individuales y colectivas para la convivencia, la resiliencia y el imaginario creativo de nuevos escenarios ante las emergencias climáticas, ambientales y socioculturales (UNESCO 2017, Varga 2007). Sus aliados son las comunidades educativas y culturales del entorno más cercano al museo, así como los grupos sociales del territorio.

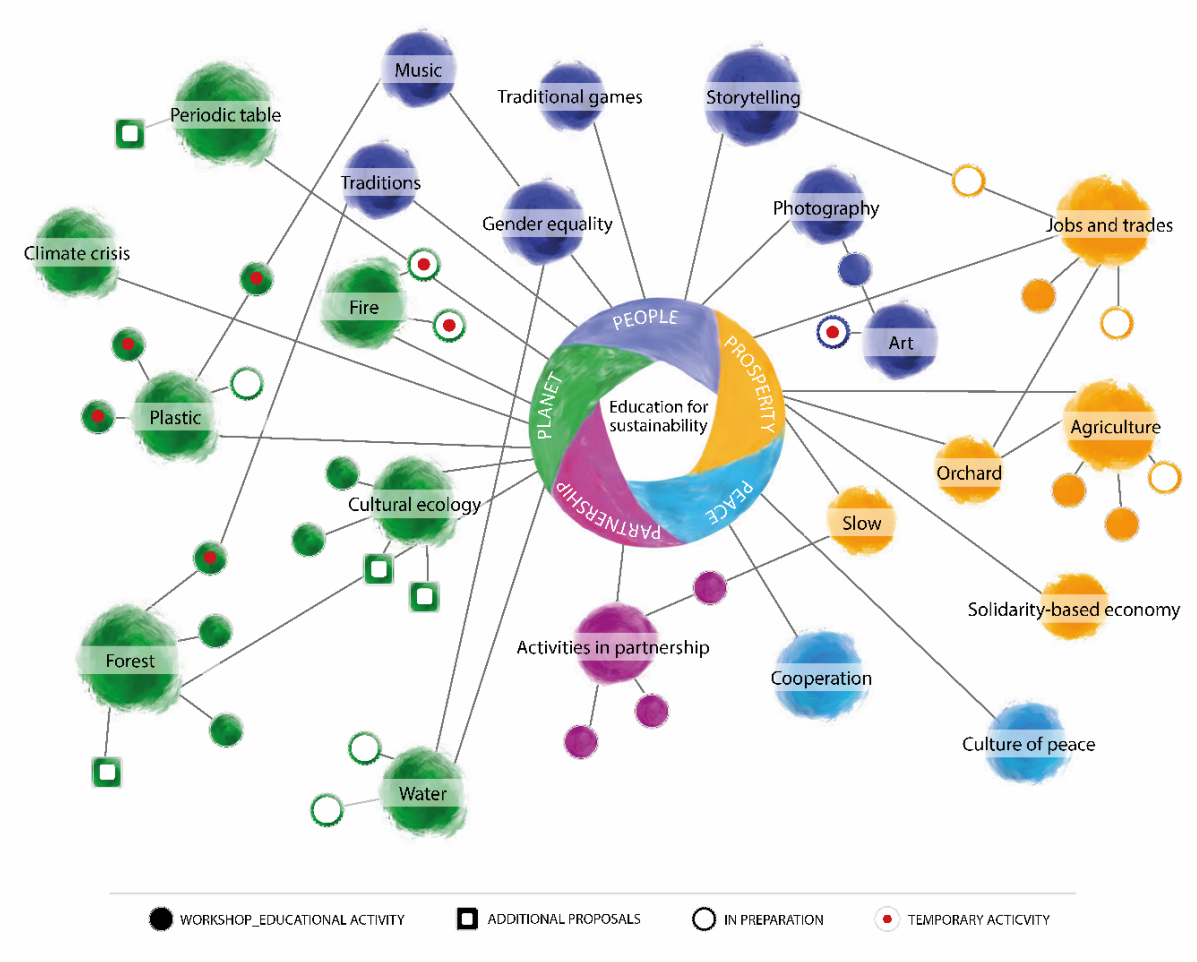

Fuente: Museu de la Vida Rural (2020)

Fig. 1: La constelación de actividades educativas del Museu de la Vida Rural

\section{Objetivos de la propuesta online que se presenta en este artículo.}

En el contexto de confinamiento domiciliario impuesto a la población durante la primera ola de la pandemia mundial originada por el virus COVID-19, el Museu de la Vida Rural continuó con su misión de generar y compartir conocimiento y promover el debate y la reflexión sobre la transformación social y el desarrollo sostenible. La voluntad de continuar poniendo los recursos educativos del museo al alcance del público a pesar del confinamiento domiciliario llevó al equipo educativo y de comunicación a ofrecer una propuesta educativa en línea, en el marco del proyecto pedagógico de educación cultural para el desarrollo sostenible. A partir del mes de abril de 2020, las educadoras del museo diseñaron y publicaron, junto con el responsable de comunicación el recurso «SOStenibilidad en juego» 
(Museu de la Vida Rural, 2020), un material educativo dirigido a las familias con niños y niñas confinados en casa.

La propuesta pretendía generar conversaciones intergeneracionales que posibilitaran cambios de actitudes y hábitos hacia la sostenibilidad, a la vez que se descubrieran de forma lúdica y a través del arte y la cultura los 17 Objetivos para el Desarrollo Sostenible establecidos por la UNESCO y la Agenda 2030 (Naciones Unidas). El contexto evidenciaba la vinculación entre la emergencia climática y sanitaria debido a la crisis causada por una pandemia mundial sin precedentes.

\section{Desarrollo de la innovación: de una actividad presencial a una propuesta virtual}

La propuesta virtual «SOStenibilidad en juego» está inspirada en una actividad presencial que el museo ofrece habitualmente en sus instalaciones. Se trata de una visita dinamizada que invita a reflexionar sobre cuál debería ser la actuación de las personas ante la emergencia climática actual, a fin de buscar unas relaciones más armoniosas y sostenibles con el planeta, la comunidad y para con nosotros/as mismos/as. A partir de la memoria que conserva el museo y a través de una serie de dinámicas, se descubren los Objetivos de Desarrollo Sostenible (ODS).

Sin embargo, la nueva propuesta que aquí se explica se concibió desde un inicio virtualmente y se basó justamente en el carácter hipertextual del entorno virtual. Ello ofrecía nuevas posibilidades para articular un relato no lineal y establecer conexiones entre recursos de naturaleza muy diversa, entre los cuales se encuentran los objetos de la colección permanente del museo.

\section{1 «SOStenibilidad en juego»}

En el momento de crear la propuesta virtual, el equipo educativo del museo asumió un doble desafío: mantener los objetivos pedagógicos de la propuesta presencial e idear recursos y dinámicas en línea que sirvieran para lograrlos, a la vez que evaluar la participación a través del retorno de los participantes. En este contexto los diseñadores de la propuesta optaron por estructurar los contenidos en torno a los 17 ODS. Los objetivos principales de esta actividad son los siguientes:

- Ser conscientes de la interdependencia y la vulnerabilidad de la vida humana y del planeta.

- Extraer las lecciones que desde la memoria del pasado nos pueden ayudar a entender el presente y proyectar un futuro mejor.

- Desarrollar la inteligencia ecológica: la capacidad para percibir conexiones entre las actividades humanas y sus consecuencias en los sistemas naturales y sociales.

- Descubrir los 17 ODS establecidos por la UNESCO en el marco de la Agenda 2030 para un Desarrollo Sostenible y conocer de qué manera colaborar para conseguirlos.

- Entender el concepto de sostenibilidad en un sentido amplio que inscribimos dentro de las llamadas 5 P: planeta, persona, prosperidad, paz y partenariado. 
- Promover la creatividad cultural para un desarrollo sostenible.

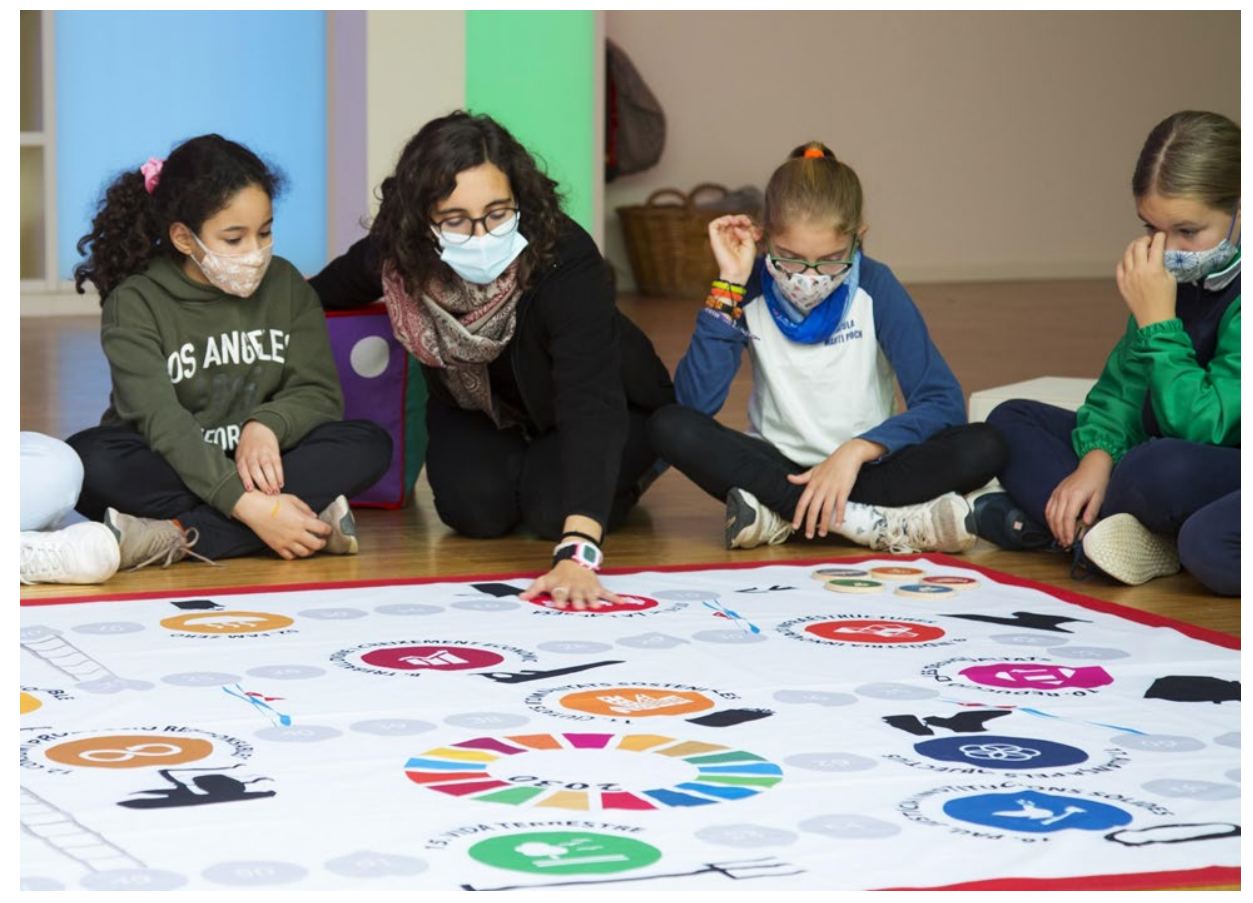

Fuente: Museu de la Vida Rural (2020)

Fig. 2: Los niños y niñas de la Escuela Vedruna de l'Espluga de Francolí realizando la actividad presencial «SOStenibilidad en juego» en los espacios educativos del museo con una de las educadoras.

Haciendo un guiño al movimiento Fridays for Future, a partir del día 29 de mayo de 2020, cada viernes de las siguientes diecisiete semanas se publicaría en la página web del museo el contenido relativo a un ODS en concreto. Dicho contenido se estructura en diferentes secciones con información que permite profundizar en cada ODS a través de propuestas literarias, científicas, cinematográficas y audiovisuales, a través de la colección de objetos y fotografías de archivo del museo y también las artes visuales y plásticas. Y todo ello se completa con una sección de buenas prácticas con propuestas que promueven la participación de los usuarios para contribuir a la consecución de los ODS.

Para incentivar la participación de los usuarios, cada ODS contiene uno o dos retos o propuestas que requieren la acción de los participantes, que pueden realizarse desde casa (y/o la escuela) y que fomentan la educación para el desarrollo sostenible. Con la etiqueta \#SOStenibilitatenJOC los participantes pueden publicar sus acciones en las redes sociales y participar en el sorteo de premios, como productos sostenibles de la tienda del museo y actividades gratuitas. Las diseñadoras de esta propuesta pensaron en incorporar la estrategia 
del sorteo con el objetivo de recoger los contenidos creados por las familias participantes y, a través de estos, realizar un análisis cualitativo de la participación y reacciones generadas (este análisis se detalla en la fase I de experimentación de la propuesta en el apartado 4.1 de este artículo).

El hilo conductor que incitaba a descubrir semanalmente un ODS a través del arte, la ciencia y el patrimonio es la metáfora de la oruga que se transforma en mariposa del escritor e ilustrador de libros infantiles Eric Carle. Del mismo modo que la protagonista del cuento infantil después de comer alimentos de todos los colores se cierra para hacer el capullo y se convierte en mariposa, se propone a los participantes profundizar en los 17 ODS para transformarse y ser más conscientes y emprender acciones en pro del desarrollo sostenible.

Las estrategias comunicativas que acompañaron las publicaciones en la página web del museo fueron varias. Cada viernes el equipo de comunicación realizaba una publicación en diferentes redes sociales. En Twitter y Facebook, las publicaciones para invitar a la participación iban acompañadas de una creación audiovisual sobre el ODS de la semana que combinaba información sobre este y su vinculación con elementos patrimoniales del museo, apuntando reflexiones en torno a la relación entre nuestros hábitos y la consecución del ODS en cuestión. ${ }^{1}$ El mismo contenido se publicaba en Instagram adaptándolo al formato de Story.

En el momento de pensar el planteamiento de fondo de este recurso online, el equipo educativo del museo intuía la necesidad de vincularlo a escuelas cercanas al proyecto educativo global del museo; escuelas que se han propuesto un trabajo a fondo sobre la sostenibilidad, así como entidades de ocio educativo y familias cercanas, para asegurar una mínima masa crítica que permita una aplicación efectiva y la obtención de un retorno de la propuesta.

Estos centros educativos se caracterizan por unos claustros de profesorado excepcionales, innovadores y dinámicos para los que el trabajo con el entorno cultural y natural es una apuesta pedagógica decidida que facilita un aprendizaje vivencial, motivador, significativo y emocional. El trasfondo es siempre el reto de la sostenibilidad y la Agenda 2030 para construir un futuro posible y deseable. El diálogo continuo entre docentes y profesionales del museo es un factor clave en el desarrollo de estos proyectos y actividades y permite también establecer los aprendizajes del alumnado.

La Escuela Vedruna de l'Espluga de Francolí es una de estas escuelas. Está situada en el mismo municipio que el museo y tanto el claustro de maestros y maestras como el alumnado acuden al museo con frecuencia para realizar actividades educativas y formativas. Este centro forma parte de la Red de Escuelas Vedruna de Catalunya, integrada por 36 centros con una larga historia y que configuran la red educativa concertada más grande de Cataluña. El año pasado, desde la Fundación Vedruna Cataluña Educación se inició un proyecto que responde a una hoja de ruta para los próximos años, que tiene como finalidad incluir los ODS en las aulas de red a través de actividades que impulsan el trabajo por la Educación para el

${ }^{1}$ https://twitter.com/MuseuVidaRural/status/1268878472002375681 
Desarrollo Sostenible y los objetivos de aprendizaje vinculados a ODS de la UNESCO (UNESCO, 2017).

\section{Resultados de la participación en la propuesta «SOStenibilitat en joc»}

\subsection{Primera fase de experimentación: participación online del público familiar}

Para evaluar la participación del público familiar en una primera fase de experimentación se recogieron los siguientes datos: por una parte, el número de visitas que obtuvo la página web que aloja la propuesta y el número de impresiones (apariciones en pantalla) de cada una de las publicaciones sobre «SOStenibilidad en juego» hechas por el museo en las redes sociales. Por otra parte, se recogió el número de publicaciones con la etiqueta \#SOStenibilitatenJOC hechas en Twitter, Instagram y Facebook por cuentas ajenas al museo y que no fueran para promocionar la iniciativa. En este segundo recuento se observó que no hubo participación en las redes sociales a través del hashtag/sorteo. No hubo ni una sola publicación por parte de las familias y, por tanto, la propuesta no tuvo la participación que en un inicio el equipo educativo del museo esperaba.

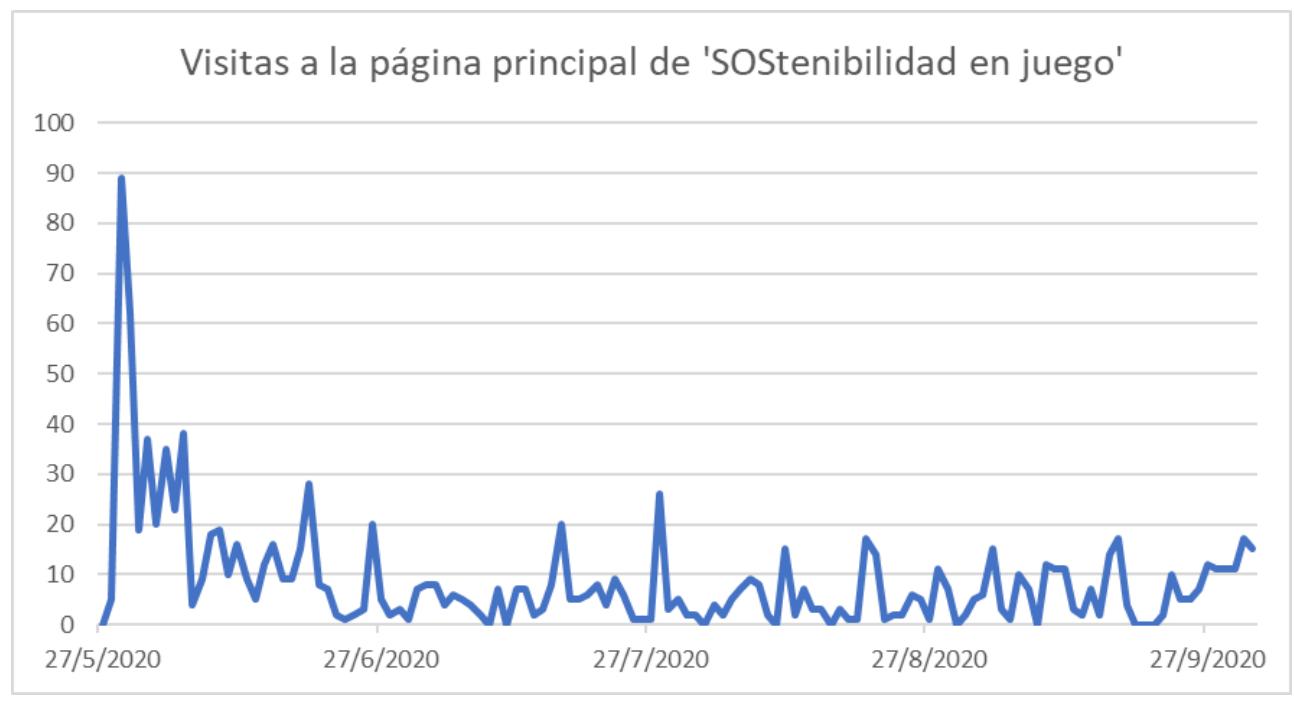

Fuente: Museu de la Vida Rural (2020)

Fig. 3: Gráfico de visitas a la página principal de «Sostenibilidad en juego» desde el día en que se lanzó la propuesta hasta la semana después de haber publicado el último ODS. 


\begin{tabular}{|l|r|r|r|r|}
\cline { 2 - 5 } \multicolumn{1}{c|}{} & Facebook & Twitter & $\begin{array}{l}\text { Stories } \\
\text { Instagram }\end{array}$ & Total \\
\hline $\begin{array}{l}\text { Página principal } \\
\text { «Sostenibilidad e } \\
\text { juego»» }\end{array}$ & 5579 & 3911 & 500 & $\mathbf{9 9 9 0}$ \\
\hline ODS 1 & 3230 & 643 & 400 & $\mathbf{4 2 7 3}$ \\
\hline ODS 2 & 4010 & 412 & 400 & $\mathbf{4 8 2 2}$ \\
\hline ODS 3 & 4459 & 573 & 400 & $\mathbf{5 4 3 2}$ \\
\hline ODS 4 & 1600 & 602 & 400 & $\mathbf{2 6 0 2}$ \\
\hline ODS 5 & 8920 & 1455 & 400 & $\mathbf{1 0 7 7 5}$ \\
\hline ODS 6 & 5698 & 978 & 400 & $\mathbf{7 0 7 6}$ \\
\hline ODS 7 & 1600 & 455 & 400 & $\mathbf{2 4 5 5}$ \\
\hline ODS 8 & 4869 & 497 & 400 & $\mathbf{5 7 6 6}$ \\
\hline ODS 9 & 3213 & 797 & 400 & $\mathbf{4 4 1 0}$ \\
\hline ODS 10 & 3527 & 618 & 400 & $\mathbf{4 5 4 5}$ \\
\hline ODS 11 & 3381 & 482 & 400 & $\mathbf{4 2 6 3}$ \\
\hline ODS 12 & 1600 & 544 & 400 & $\mathbf{2 5 4 4}$ \\
\hline ODS 13 & 4364 & 1167 & 400 & $\mathbf{5 9 3 1}$ \\
\hline ODS 14 & 4201 & 466 & 400 & $\mathbf{5 0 6 7}$ \\
\hline ODS 15 & 5869 & 575 & $\mathbf{1 1 ~ 8 4 4}$ \\
\hline ODS 16 & 1106 & $\mathbf{4 1 4 8}$ \\
\hline ODS 17 & & & $\mathbf{6 2 8 7}$ \\
\hline & 5076 & 400 & \\
\hline
\end{tabular}

Fuente: Museu de la Vida Rural (2020)

Tabla 1. Impresiones o número de veces que han aparecido en pantalla las publicaciones en redes sociales sobre la propuesta «Sostenibilidad en juego» y cada uno de los ODS

La falta de participación en las redes sociales a través del hashtag \#SOStenibilitatenJOC y en el sorteo correspondiente supone una falta importante de evidencias para poder evaluar el impacto de la propuesta a nivel cualitativo. Aun así, se han dado algunos hechos que son indicadores significativos de la calidad de esta propuesta educativa y ponen de relieve su repercusión y apropiación por parte de otros agentes de la comunidad educativa virtual, como por ejemplo la incorporación de la propuesta en una recopilación de materiales para trabajar 
los ODS en clave educativa hecho por Lucía Vázquez García, consultora en los Objetivos de Desarrollo Sostenible y la Agenda 20302.

\subsection{Segunda fase de experimentación: activación de la propuesta online en centros educativos cercanos al museo}

Después de valorar los resultados no satisfactorios de la primera fase de experimentación con público familiar, el equipo educativo se plantea la hipótesis de que, para conectar con las familias, es necesario hacerlo desde la escuela. Por ello inicia una prueba piloto del funcionamiento de este material en centros educativos combinando virtualidad y presencialidad.

Se trata de la Escuela Vedruna de l'Espluga de Francolí, con la que el museo ya ha organizado varias actividades, ya que comparten el reto de la sostenibilidad. Durante el primer trimestre del curso 2020-2021 una formación online sobre arte, educación y resiliencia fue ofrecida por el museo con motivo de la exposición temporal «Només Anada», dedicada al fenómeno migratorio. Se organizó también un encuentro del claustro de maestros y maestras en los nuevos espacios educativos del museo inspirados en la Agenda 2030 y todos los niños y niñas de $1^{\circ}$ a $6^{\circ}$ de educación primaria acudieron al museo a realizar la visita y taller presencial «Sostenibilidad en juego». Estas actividades sirvieron de precedente para activar la propuesta online en las aulas de la escuela, y la primera ocasión para hacerlo fue durante la semana de la Gran Recogida de Alimentos organizada por el Banco de Alimentos de Cataluña (BdA) que se celebró el pasado mes de noviembre.

El BdA es una ONG que tiene como uno de sus objetivos principales la lucha contra el derroche alimentario, recuperando excedentes alimenticios aptos para el consumo humano y así luchar contra la pobreza, haciendo llegar los alimentos recuperados a personas en situación de precariedad alimentaria del entorno. Entre diferentes programas y campañas, el BdA organiza anualmente la Gran Recogida de Alimentos, una semana intensiva en la que se promueven donaciones de alimentos por parte de la ciudadanía en un acto de solidaridad y en la cual la comunidad educativa de la Escuela Vedruna de l'Espluga participó recogiendo un total aproximado de $1000 \mathrm{~kg}$ de alimentos del 16 al 21 de noviembre de 2020, según el coordinador de la recogida que tuvo lugar en el centro.

Esta acción solidaria significó una incidencia directa por parte de la comunidad educativa de la escuela en el ODS2 «Hambre cero». A través de la donación de alimentos se incidió concretamente en la meta 2.1 del ODS2: «para 2030, poner fin al hambre y asegurar el acceso de todas las personas, en particular los pobres y las personas en situaciones vulnerables, incluidos los lactantes, a una alimentación sana, nutritiva y suficiente durante todo el año» (United Nations).

El equipo de maestros que coordinó la recogida de alimentos y el desarrollo de actividades durante la semana asegura que, en comparación con años anteriores, en esta ocasión se logró una participación mucho más elevada por parte de las familias en la acción solidaria y, por

${ }^{2}$ https://www.educacionysostenibilidad.com/blog/ods-actividades-recursos-ninos/ 
tanto, un número de kilos de alimentos mayor. El coordinador del proyecto ODS de la escuela afirma que ello fue debido al conjunto de actividades que se llevaron a cabo durante los días previos a la recogida de alimentos con el objetivo de promover e incentivar que toda la comunidad educativa (alumnos/as, profesorado y familias) colaborara en la causa. Los niños y niñas de $1^{\circ}$ a $6^{\circ}$ de educación primaria participaron en estas actividades que los maestros y maestras diseñaron en base a los materiales que se recogen en el ODS2 de la propuesta online «SOStenibilidad en juego». Seguidamente, las autoras explican algunos ejemplos de cómo los y las maestras se apropiaron de estos materiales, adaptándolos y creando actividades para diferentes niveles educativos, así como algunos de los resultados finales.

A través de la observación de las imágenes del artista Peter Menzel, 3 en la clase de $6^{\circ}$ de educación primaria se abrió un debate sobre las grandes diferencias culturales y económicas en el mundo a través de la comida. Después del debate, se les pidió a los y las estudiantes que escribieran una carta para concienciar sobre el problema del hambre en el mundo. Claudia, de 12 años, tituló su carta «iQué afortunada soy!», que fue publicada en la edición de diciembre de 2020 de la revista El Francolí, y donde explicaba cómo informó a su padre y madre de la iniciativa que se estaba llevando a cabo en el colegio y cómo, junto a ellos, fue a comprar alimentos para participar en la acción solidaria en familia.

Después de visualizar el corto animado We won't accept hunger, 4 se propuso a los alumnos y alumnas de $5^{\circ}$ de educación primaria que realizaran una dinámica en la que, a través del consenso, debían llegar a un acuerdo para dar respuesta a la siguiente situación: «Imaginad, por un momento, que sois los grandes líderes del mundo y que tenéis el poder para cambiar las cosas con vuestras decisiones. Si pudierais hacerlo, ¿cuáles serían los tres problemas que solucionaríais más urgentemente para conseguir un mundo más justo, equitativo y sostenible?» El resultado final fue el consenso de todo el grupo en tres problemas: la corrupción, el cambio climático y el hambre.

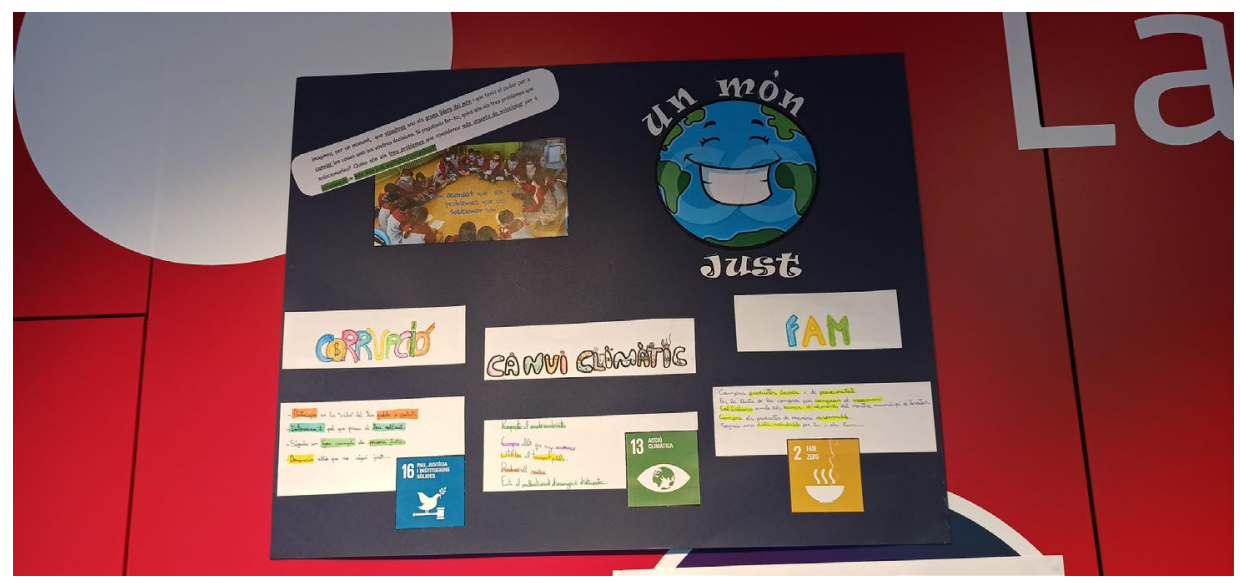

\footnotetext{
${ }^{3} \mathrm{http}: / /$ menzelphoto.com/galleries/hungry-planet/ ${ }^{4}$ https: $/ /$ www.youtube.com $/$ watch? $=$ Qt4FxzDIRm $8 \&$ feature $=$ emb title\&ab_channel $=$ Glop olis
} 
Fuente: Escola Vedruna de l'Espluga de Francolí (2020)

\section{Fig. 4 Resultado de la actividad realizada con los alumnos y alumnas de $5^{\circ}$ de educación primaria}

A partir del interactivo del diario Ara.cat,5 los niños y niñas de $3^{\circ}$ de educación primaria conocieron y clasificaron diferentes frutas y verduras por temporadas (primavera, verano, otoño e invierno) con el objetivo de sensibilizar a los alumnos y orientarlos en cómo evitar el desperdicio alimentario. Una vez hecho esto, se les propuso inspirarse en las imágenes del artista Archimboldo para crear composiciones con las frutas y las verduras de temporada.

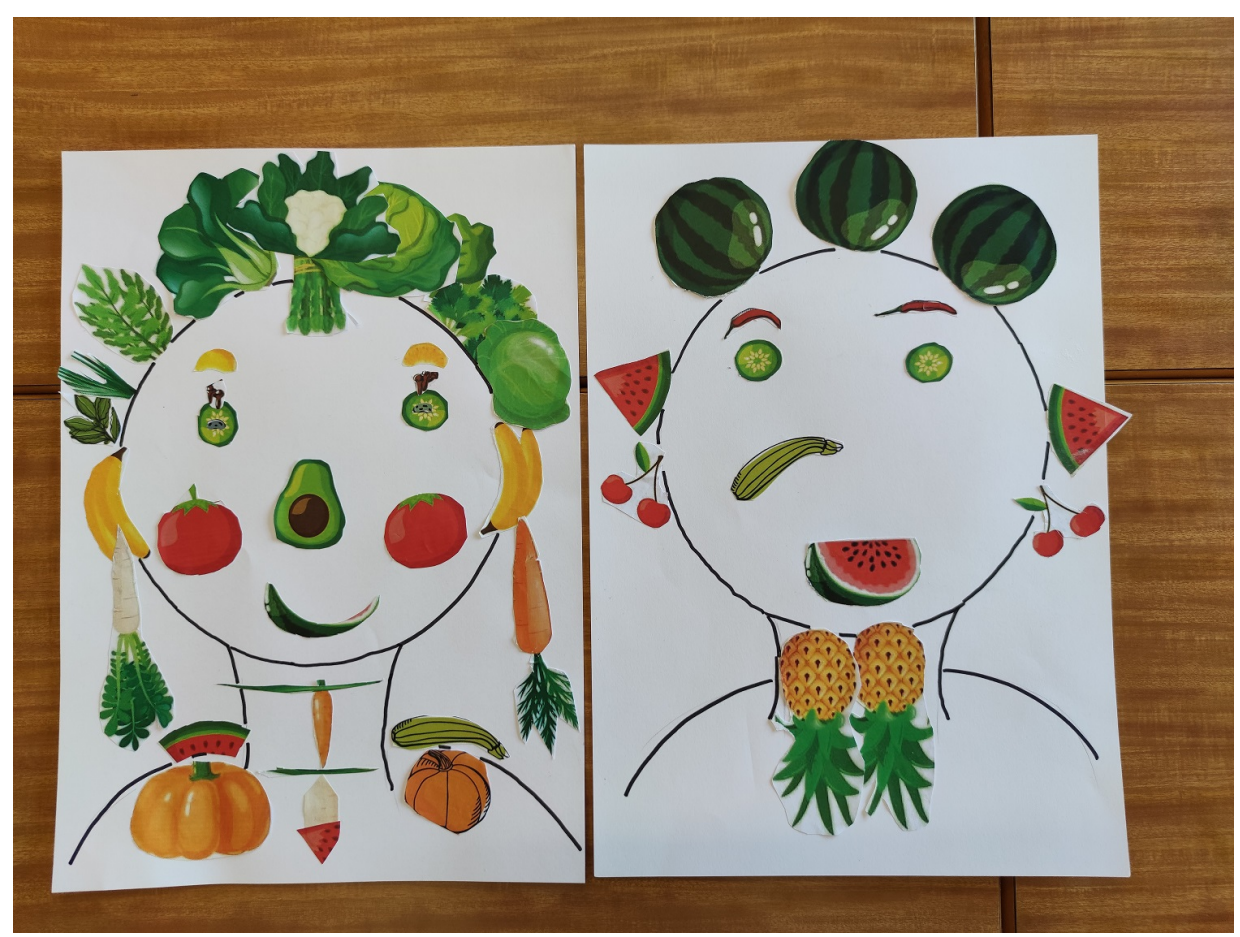

Fuente: Escola Vedruna de l'Espluga de Francolí (2020)

Fig. 5 Resultado de la actividad realizada con los alumnos y alumnas de $3^{\circ}$ de educación primaria

Los alumnos de $2^{\circ}$ de educación primária visualizaron el cortometraje animado One human family 6 con la premisa de fijarse bien en los detalles. Seguidamente hicieron un ejercicio donde se les pedía que se imaginaran a sí mismos actuando dentro del cortometraje y se les planteó una serie de preguntas: ¿Qué haríais si no llegarais a la comida? ¿Podríais ayudar a los demás de otra manera y conseguir que todo el mundo pudiera comer? ¿Podríamos hacerlo

\footnotetext{
${ }^{5} \mathrm{https}$ ://interactius.ara.cat/alimentstemporada ${ }^{6}$ https://www.youtube.com/watch?v=qhU5JEd$\underline{X R o \& f e a t u r e}=e m b$ title \&ab channel $=$ CaritasInternationalis
} 
también en la vida real? Una vez terminado el debate, observaron dos imágenes del fotógrafo Peter Menzel y consideraron las siguientes preguntas para continuar con la reflexión: ¿pensáis que todo el mundo tiene derecho a comer de todo? ¿Todos pueden conseguir los alimentos que quieren? Los alimentos que tenemos, ¿siempre son saludables? Finalmente, los alumnos completaron una pirámide de los alimentos y la compartieron con el resto de la escuela colocándola en la entrada del centro junto a otros resultados de las actividades realizadas en otros cursos.

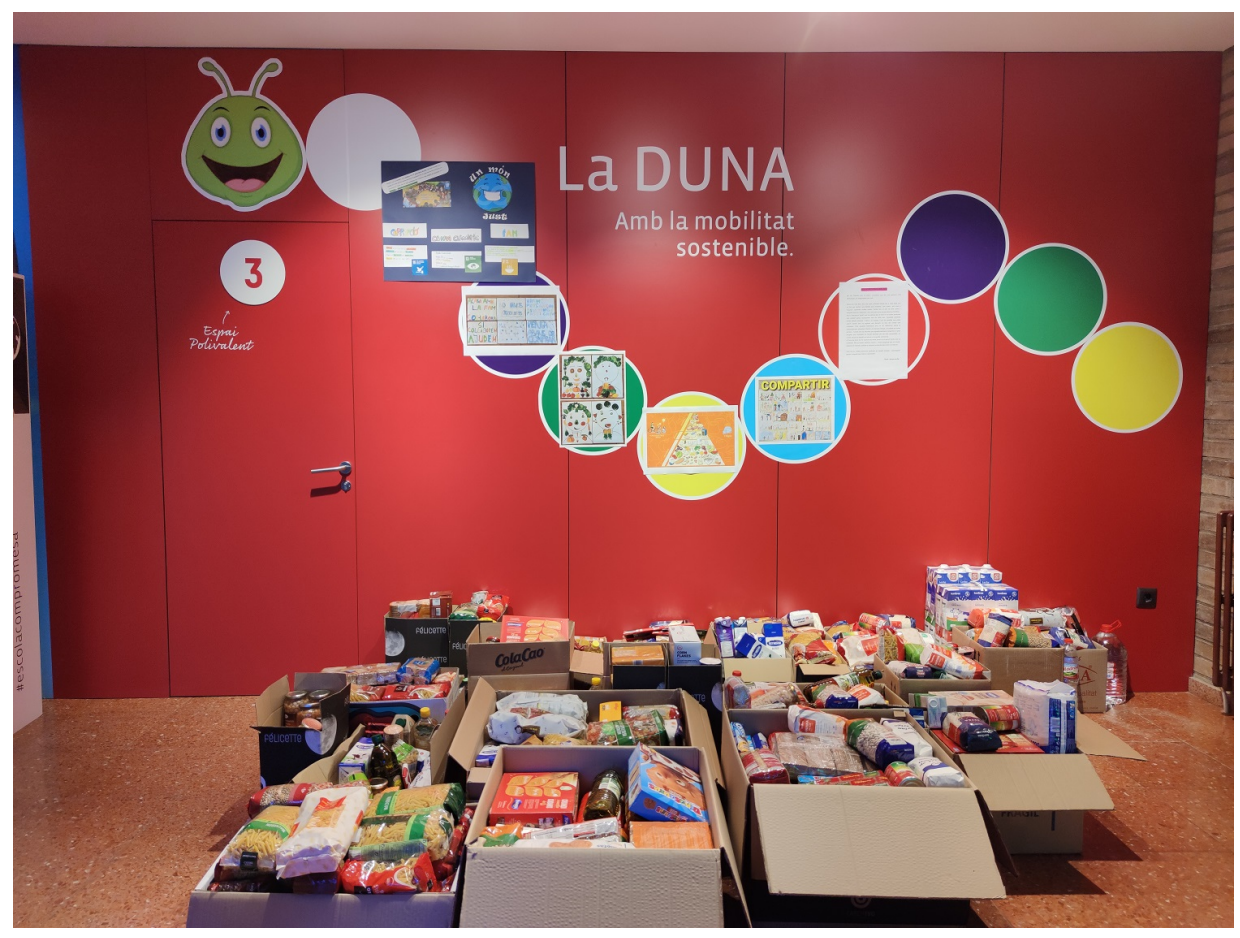

Fuente: Escola Vedruna de l’Espluga de Francolí (2020)

\section{Fig. 6 Los trabajos de los alumnos y alumnas de $1^{\circ}$ a $6^{\circ}$ de educación primaria realizados durante la semana de recogida de alimentos}

A través de estas actividades, durante la semana de la recogida de alimentos, se incidió también en el ODS4 «Educación de calidad», que persigue «garantizar una educación inclusiva y equitativa de calidad y promover oportunidades de aprendizaje permanente para todos», comprendiendo la «contribución de la cultura al desarrollo sostenible» (United Nations), ya que los y las maestras aprovecharon el material educativo online referente al ODS2 que la web del museo alberga para sensibilizar a los niños y niñas sobre la problemática del derroche y la pobreza alimentaria, tema clave en el desarrollo sostenible indicado en el ODS2.

En cuanto al impacto cuantitativo que ha tenido la propuesta en esta segunda fase de experimentación, el número de maestros y alumnos que han usado algún material de 
«Sostenibilidad en juego» es de 103 alumnos y 14 profesores de la Escuela Vedruna de l'Espluga de Francolí. Según el coordinador del proyecto ODS del centro, algunas familias han podido conocer la propuesta online del museo a través de sus hijos e hijas, pero no disponemos de datos concretos en cuanto al número de familias. Aun así, en el siguiente gráfico se puede observar que, aparte del mes de junio (el mes de la campaña de lanzamiento y promoción del ODS2), fue durante el mes de noviembre de 2020 cuando la página web del ODS 2 obtuvo más visitas. Es decir, durante la semana de la recogida de alimentos en la Escuela Vedruna, cuando se realizaron las actividades anteriormente descritas.

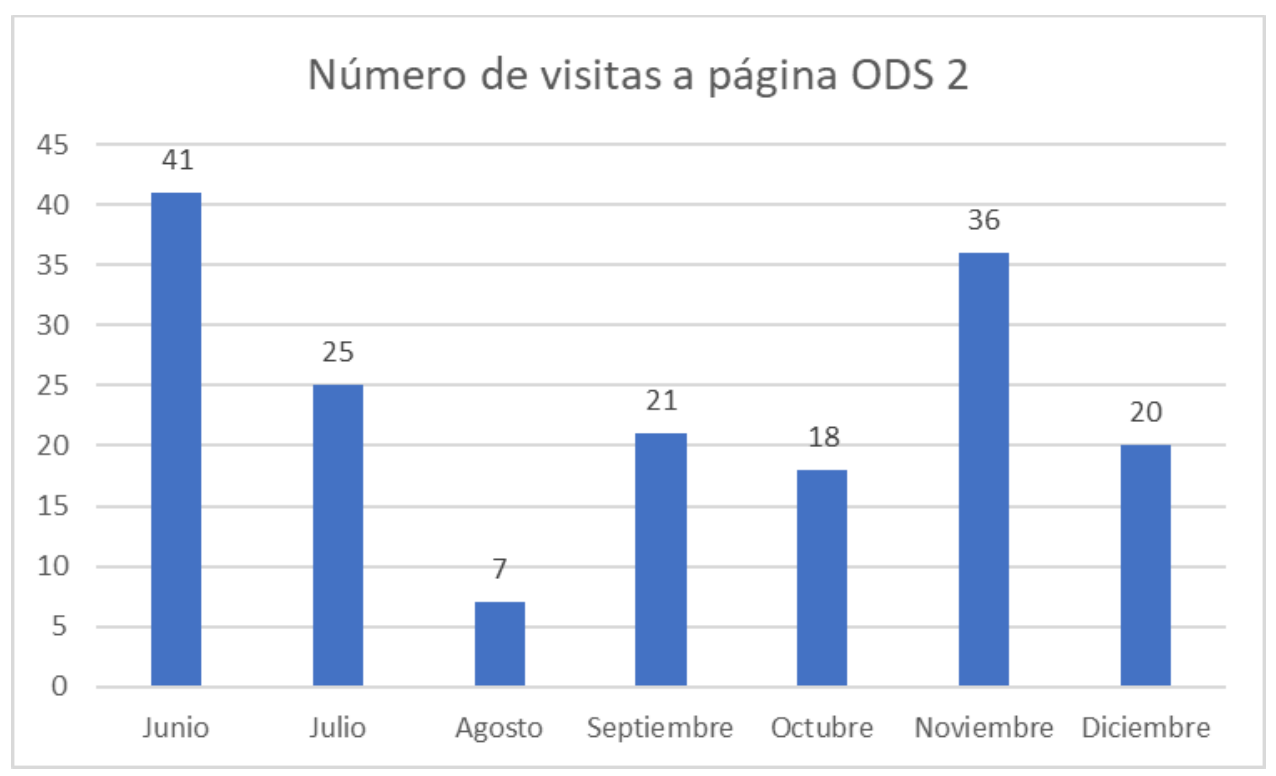

Fuente: Museu de la Vida Rural (2020)

Fig. 7 Número de visitas a la página web del ODS 2 desde su lanzamiento hasta el mes de diciembre de 2020

Por último, los equipos directivos de las 36 escuelas de la Fundació Vedruna Catalunya y sus correspondientes asociaciones de padres y madres conocen «SOStenibilidad en juego» gracias al programa formativo sobre los ODS de la Fundación, en el que el pasado 30 de enero de 2021 el coordinador del proyecto ODS de la Escuela Vedruna de l'Espluga compartió la propuesta educativa online del museo y explicó las acciones y actividades que se desarrollaron en la escuela durante la semana de la recogida de alimentos.

Como se ha podido observar, la Escuela Vedruna de l'Espluga de Francolí ha incorporado la Educación para el Desarrollo Sostenible en su proyecto de centro, focalizando sobre todo en el trabajo por el ODS2 «Hambre cero», y también los ODS 3 y 17, «Salud y bienestar» y «Alianza por los objetivos», respectivamente. Se han programado futuras acciones como, por ejemplo, una jornada de plogging, una nueva modalidad deportiva que combina el ejercicio físico con el cuidado del medio ambiente y que consiste en recoger residuos del entorno 
natural mientras se practica jogging. Para la ocasión, y de modo similar a lo hecho con el ODS2, los maestros y maestras van a diseñar nuevas actividades basadas en el contenido del ODS «Salud y bienestar» de la propuesta online «Sostenibilidad en juego», que vinculen la salud física, mental y emocional de las personas con el entorno y con la naturaleza.

\section{Conclusiones}

Tras observar los resultados de la primera y segunda fase de experimentación de la propuesta, las autoras concluyen que cuando se lanzan propuestas educativas virtuales la participación por parte de las familias todavía no se produce de manera espontánea. Durante la primera fase de experimentación de la propuesta no se recibió ningún tipo de retorno por parte de las familias, que estaba previsto a través de su participación en las redes sociales. Por tanto, es necesario vincular la propuesta online a agentes educativos cercanos al museo. Además, las autoras han notado que el material online cobra mucho más sentido cuando se puede combinar con actividades presenciales en el museo y/o en el centro escolar. Lo online no substituye a lo presencial, sino que lo complementa, del mismo modo que el museo (online) y la escuela se complementan y retroalimentan. «Sostenibilidad en juego», por ejemplo, es una propuesta virtual versátil que los y las maestras pueden aprovechar para el trabajo en el aula según sus intereses y objetivos. La aproximación educativa a temas relacionados con la sostenibilidad es importante para conseguir los ODS y, como se ha podido observar en este artículo, las propuestas educativas como «Sostenibilidad en juego» que están diseñadas desde esa óptica son fáciles de relacionar con proyectos escolares.

En esta misma línea, también es interesante destacar que la página web del museo y, sobre todo, su apartado de educación, 7 se convierten en un repositorio de recursos educativos de acceso libre, abiertos a toda la comunidad educativa, que fomentan la reflexión y la participación en torno a las artes y la cultura, el patrimonio etnológico y la sostenibilidad medioambiental, social y cultural. Los docentes pueden apropiarse de estos contenidos para dar respuesta a sus necesidades y desarrollar actividades propias, como hicieron las maestras de la Escuela Vedruna. Así como el equipo educativo del museo lo ha hecho con esta escuela, la siguiente fase de experimentación de «Sostenibilidad en juego» consistirá en testear la propuesta con un grupo de familias cercanas al museo con el objetivo de ir haciendo crecer la comunidad educativa de la que el museo forma parte. Como mejoras a realizar en la propuesta virtual, el equipo educativo se propone integrar estas experiencias en la propuesta misma. Es decir, actualizar el contenido de «Sostenibilidad en juego» constantemente con las actividades y reacciones derivadas de su uso por parte de las escuelas y familias participantes.

Desde el punto de vista de las autoras, en el mundo de educación y museos el formato online ayuda a superar las barreras del distanciamiento físico, pero la respuesta que implica un impacto cualitativo va ligada a la presencialidad. A través de la experimentación de esta propuesta, las autoras concluyen que el éxito de las actividades educativas virtuales depende del contacto cercano y directo con los participantes/usuarios.

\footnotetext{
${ }^{7}$ https://museuvidarural.cat/educacio/
} 


\section{Referencias}

ALGARRA, D. (2015). El comú català. Barcelona. Potlatch edicions

KAGAN, S. (2015). «Artistic research and climate science: transdisciplinary learning and spaces of possibilities», en Journal of Science Communication Vol. 14, issue 01. < https://doi.org/10.22323/2.14010307> [Consulta: 19 de febrero de 2021].

MUSEU DE LA VIDA RURAL. (2020). SOStenibilitat en joc. $<$ https://museuvidarural.cat/sostenibilitat-joc/ $\geq$ [Consulta: 19 de febrero de 2021].

UNITED NATIONS. Agenda 2030. $<$ https://www.un.org/sustainabledevelopment/es/development-agenda/ $\geq$ [Consulta: 19 de febrero de 2021].

UNESCO. (2006). Road map for arts education. París: UNESCO.

UNESCO. (2017). Education for Sustainable Development Goals. Learning Objectives. París: UNESCO. <https://unesdoc.unesco.org/ark:/48223/pf0000252423 > [Consulta: 19 de febrero de 2021].

VARGA, A.; BREITING, S.; MAYER, M.; MORGERSEN, F.(2007) Educación para el desarrollo sostenible. Barcelona. Graó Editorial 